\title{
O discurso de Antônio Carlos Pacheco e Silva sobre a psicanálise: São Paulo, 1926-1979 \\ Pacheco e Silva's discourse over psychoanalysis: São Paulo, 1926-1979
}

\author{
Gustavo Alarcão ${ }^{a, b}$ \\ (D) https://orcid.org/0000-0002-7647-5323 \\ E-mail: gustavogilalarcao®yahoo.com.br
}

\section{André Mota ${ }^{\mathrm{a}, \mathrm{c}}$}

(D) https://orcid.org/0000-0002-5697-8628

E-mail: andremotaıß@gmail.com

anniversidade de São Paulo. Faculdade de Medicina. Departamento de Medicina Preventiva. São Paulo, SP, Brasil.

buniversidade de São Paulo. Faculdade de Medicina. Hospital das Clínicas. Instituto de Psiquiatria. Serviço de Psicoterapia. São Paulo, SP, Brasil.

'Universidade de São Paulo. Faculdade de Medicina. Museu Histórico Carlos da Silva Lacaz. São Paulo, SP, Brasil.

\section{Resumo}

Qualquer estudioso da história do campo psi reconhece a dimensão das tensões existentes entre psicanálise e psiquiatria. Ao mesmo tempo, a perspectiva histórica nos mostra interligações e influências mútuas nos planos teóricos, práticos, institucionais e políticos entre essas disciplinas. No caso paulista, Antônio Carlos Pacheco e Silva (1898-1988) influenciou gerações de psiquiatras formadas nas escolas de psiquiatria que chefiou entre 1923-1968. Sua história tem sido estudada sob diferentes perspectivas, havendo uma lacuna sobre sua posição com relação à psicanálise. Este artigo procura rever essa lacuna histórica, baseando-se na análise dos documentos do próprio psiquiatra sobre a psicanálise, que demonstram objetivamente sua posição. Pretendemos, com isso, contribuir para a compreensão da história do campo psi em São Paulo. Palavras-chave: História da Psiquiatria; História da Psicanálise; Antônio Carlos Pacheco e Silva.

\section{Correspondência}


Abstract

Any Psychology scholar would recognize the extent of existing tensions between Psychoanalysis and Psychiatry. At the same time, the historical perspective shows us interconnections and mutual influences in the theoretical, practical, institutional and political planes between these disciplines. In the case of São Paulo, Antônio Carlos Pacheco e Silva (1898-1988) influenced generations of psychiatrists graduated in Psychiatry schools that he directed between 1923-1968. His history has been studied from different perspectives, with a gap on his stance with regard to Psychoanalysis. This article aims to review this historical gap, being based on the analysis of the psychiatrist's own papers about Psychoanalysis. We seek to contribute to the understanding of the history of the Psychology field in São Paulo.

Keywords: History of Psychiatry; History of Psychoanalysis; Antônio Carlos Pacheco e Silva.
O heterogêneo campo psi estabelece-se em São Paulo a partir do último quartel do século XIX e consolida-se no século XX, entre 1930-196o. Sua implantação, consolidação e institucionalização ocorrem segundo características muito particulares de cada região e para cada disciplina (Mezan, 2014). Deve-se levar em conta que os aspectos geopolíticos, teórico-conceituais e prático-profissionais não são de fácil compreensão e articulação. Assim, a análise histórica interessada em analisar continuidades e rupturas, disputas, tensões e concorrências torna-se útil, uma vez que problematiza questões complexas de âmbitos cujas histórias são igualmente complexas.

Antônio Carlos Pacheco e Silva (1898-1988), chefe de Psiquiatria na Faculdade de Medicina da Universidade de São Paulo (FM-USP) e da Escola Paulista de Medicina (EPM) entre 1936 e 1968, foi um profissional de muito destaque acadêmico. Representante da tradicional elite paulista, que se transferia das fazendas de café para formar o parque industrial e a vida urbana na capital, tornou-se também um homem de muito poder, algo calcado em suas relações pessoais e políticas. A ascensão de sua carreira inicia-se com a nomeação ao cargo de diretor do Hospital do Juquery, ainda muito jovem (26 anos). Sua extensa produção de textos tem sido estudada sob diferentes perspectivas. Entre essas abordagens, falta analisar de forma mais consistente a posição do psiquiatra com relação à psicanálise.

A partir de fins de 1930, a psiquiatria do Juquery transferiu-se para a cidade de São Paulo, que crescia em ritmo vertiginoso, desorganizado e muito bem explicitado por Sevcenko (2004, p. 30):

A história do crescimento explosivo de São Paulo não decorre de seus potenciais intrínsecos, como sempre pretende fazer crer a propaganda populista, nem tampouco comporta alguma gênese orgânica ou alguma diretriz estruturadora. Ela manifesta os profundos desequilíbrios econômicos, sociais e regionais, característicos do subdesenvolvimento do país. O crescimento desmesurado da cidade compõe assim a aflição crescente de gentes deslocadas compulsoriamente de suas origens rurais e arrastadas para o destino imprevisível da precariedade das periferias e da inconsistência do mercado de trabalho. 
Nessa transição, Pacheco apresentava-se como representante da modernidade, que buscava esquecer o passado (ainda que bem próximo) dos manicômios e das já problemáticas consequências da psiquiatria de seu tempo. Poder-se-ia pensar que a relação entre Pacheco e a psicanálise seria de complementaridade, já que esta também chegava a São Paulo com ares de modernidade, ligada à elite e à intelectualidade e buscando estabelecer-se como campo pela iniciativa de alguns médicos - dentre estes, Franco da Rocha e Durval Bellegarde Marcondes, concorrente direto de Pacheco pela cátedra da FM-USP (Moretzsohn, 2015).

Pois a história nos mostra outro desfecho. Mesmo reconhecendo a penetração da psicanálise em diversos países europeus e nos Estados Unidos, Pacheco se posicionará desde o começo com muitas resistências a ela. Essa posição interferiu na configuração do heterogêneo campo psi da cidade, permeado de tensões internas, exemplificadas pelas ações de médicos da década de 1950: havia a tentativa de manter a psicanálise como prática exclusiva da medicina, alimentando desconfianças sobre a atuação clínica de quaisquer outros profissionais, como os psicologistas, que se tornariam psicólogos oficialmente reconhecidos em 1962 (Marcondes, 1955).

É na década de 1950 que se acirraram os debates sobre quem deveria ou não exercer psicanálise. Muitos psicanalistas eram médicos de formação, liderados por Durval Marcondes - que trabalhava para a criação da Sociedade Brasileira de Psicanálise de São Paulo (SBPSP), entre 1937-1951 (após a frustrada tentativa de 1927, na qual a organização foi constituída, mas teve vida curtíssima) -, e defendiam a possibilidade de não médicos exercerem a psicanálise. Esse fato criava uma questão eminentemente política, já que, por outro lado, havia um grupo de psiquiatras que defendia o exercício exclusivo da psicanálise por médicos. O I Congresso Latino-Americano de Saúde Mental, de 1954, realizado na Clínica Psiquiátrica da FM-USP, evidencia essa questão quando da aprovação da moção de defesa da exclusividade de médicos no exercício daquela área:

Tendo em vista que a prática da psicoterapia, inclusive a psicanálise corresponde ao exercício da medicina, que a legislação de todos os países reserva aos portadores do diploma médico, recomenda que os poderes competentes dos países latino-americanos promovam os meios necessários a tomar efeito o princípio legal segundo o qual a prática de qualquer modalidade de psicoterapia por não diplomados em medicina é infração penal e, como tal, passível de punição. (Congresso LatinoAmericano de Saúde Mental, 1954, p. 267)

Como áreas independentes, psicanálise e psiquiatria partilhavam territórios que por vezes se interseccionavam tanto no plano das ideias como no das práticas. Esses cruzamentos de interesse produziram concorrências explícitas, como nas várias tentativas de regulação da atuação clínica, ou implícitas, como no capital simbólico que produziram na sua relação com a sociedade: não há ato desinteressado (Bourdieu, 2003).

A história se interessa pelo humano, seus fatos e suas falas no tempo passado, o que exclui os fatos naturais (Reis, 2006). Nessa direção, apoiamo-nos, metodologicamente, numa concepção de realidade histórica constituída por discursos e pelas relações de poder entre eles (Foucault, 2006). Isso porque o que compõe o campo da construção de uma determinada realidade é a identificação e descrição dos discursos envolvidos em certo tempo histórico, bem como o reconhecimento e a interpretação dos modos de relação entre eles. A história investiga esse processo no tempo, usa de teorias e hipóteses para repensar a materialidade inequívoca da presença humana e de suas instituições. Esta análise é subsidiada pela documentação histórica composta por textos de Pacheco e Silva sobre a psicanálise. Ao investigar essa história, esperamos contribuir com o embasamento dos posicionamentos críticos diante das rupturas e permanências das quais a dimensão histórica necessita em sua formulação (Alarcão; Mota; Lotufo Neto, 2016).

\section{Hegemonia e hierarquia: psicanálise é ramo da medicina?}

Entrar em disputa com a medicina para qualquer área, em qualquer contexto e sob qualquer justificativa é desafiar uma corporação poderosa, entranhada capilarmente na estrutura social 
(Freidson, 2009). O processo de emancipação dos ramos que compunham o campo psi foi complexo; medicina e psiquiatria formavam o tronco inicial da clínica a partir do qual se desmembram as disciplinas subsequentes. É conhecido que, até 1950, esse território era partilhado por psiquiatras e psicanalistas - cujos agentes eram em sua maioria médicos. Os médicos Sigmund Freud, Jacob Levy Moreno, Carl Gustav Jung e Ludwig Binswanger construíram as principais áreas clínicas - os ramos -, que se tornariam cada vez mais independentes da psiquiatria organicista tradicional: psicanálise, psicodrama, psicologia analítica e fenomenologia existencial, respectivamente. A chegada de psicólogos e outros profissionais à clínica é um pouco mais tardia, ocorrendo a partir de 1950; até então, alguns exemplos mais circunscritos podem ser observados, como é o caso das visitadoras psiquiátricas da higiene mental e educação sanitária em São Paulo (Maio, 2010).

Não foi um processo isento de tensões, com as principais delas incidindo sobre a psicanálise (Zaretsky, 20o6). Esse argumento pode ser comprovado analisando-se o texto e o contexto no qual Sigmund Freud (2006) publica, em 1926, A questão da análise leiga. Enfrentando os dilemas relativos à acusação de charlatanismo contra Theodor Reik em Viena, ${ }^{2}$ Freud (2006, p. 283) escreve:

Pois não consideramos absolutamente conveniente para uma psicanálise ser devorada pela medicina e encontrar seu último lugar de repouso num livro de texto de psiquiatria sob a epígrafe "Métodos de Tratamento", juntamente com procedimentos tais como sugestão hipnótica, auto-sugestão e persuasão, que, nascidas da nossa ignorância, têm de agradecer a indolência e a covardia da humanidade por seus efeitos efêmeros. Merece melhor destino e, pode-se esperar, o terá.

A despeito de sua influência na psicanálise, a posição de Freud em defesa da análise praticada por não médicos não era apoiada por muitos, permanecendo uma questão bastante controversa.
Nos Estados Unidos, a psicanálise foi incorporada atrelada à medicina, e seu exercício ficou durante anos restrito aos médicos. No Brasil, Rio de Janeiro e São Paulo foram estados nos quais a psicanálise manteve-se independente da medicina, ainda que bem próxima, enquanto no RS ocorreu o oposto (Torquato; Rocha, 2016). Hoje, é consenso que a psicanálise não é um ramo da psiquiatria e nem da medicina (Pereira, 2014), mas uma área específica, fundamentada num saber e numa prática profissional, organizada em instituições, pautada por princípios éticos e inserida no cotidiano da sociedade em que se instala.

Em São Paulo, a penetração da psicanálise se dá por diferentes caminhos já explorados pela história (Coimbra, 1995; Oliveira, 2006; Torquato; Rocha, 2016). São fatos conhecidos, desde a primeira publicação de Franco da Rocha (1930)³ sobre Freud, os esforços de Durval Marcondes para sua institucionalização - via Associação Psicanalítica Internacional (IPA) -, conquistada em 1951, e sua inserção na cultura e no direito. Na cátedra de Psiquiatria da FM-USP, pode-se notar o peso da instituição médica e das diretrizes ditadas por Pacheco e Silva nesse processo. Segundo Oliveira (2006), enquanto Pacheco foi o catedrático da psiquiatria paulista (entre as décadas de 19301970), a psicanálise não encontrou espaço no rol de procedimentos clínicos, contrariando o que se observava em vários outros lugares.

\section{As parcialidades da memória: o que já foi dito sobre a posição de Pacheco e Silva?}

A literatura nos mostra até agora uma polarização sobre a posição de Pacheco diante da psicanálise. Um grupo de autores afirma que Pacheco e Silva não fazia oposição à psicanálise, enquanto outro grupo afirma que o psiquiatra era efetivamente contrário a ela.

No primeiro grupo encontramos os trabalhos de Seixas (2012), Neves (2008) e Amaro (2003).

\footnotetext{
20 psicanalista não médico Theodor Reik (1888-1969) foi acusado, em Viena, de charlatanismo por um ex-paciente que era médico. 3 Essa obra foi publicada pela primeira vez em 1920, mas consultamos a segunda edição, publicada em 1930.
} 
Eles apoiam-se no testemunho de Jorge Wohwey Ferreira Amaro, que atuou na Clínica Psiquiátrica entre 1963-200o e fundou, dentro dela, o Serviço de Psicoterapia, entre 1963-1965. Amaro era um psiquiatra que fizera análise pessoal e tivera formação em Psicanálise na SBPSP. Além de seu testemunho pessoal, Amaro publicou em 2003 o artigo mais citado sobre a história do Instituto de Psiquiatria da FM-USP, no qual reiterava a falta de oposição de Pacheco e Silva à psicanálise. Trata-se de um texto essencialmente memorialista, carente de análise crítica e contextualização. Outro argumento que precisa ser contextualizado é o usado por Neves (2008), que afirma que o psiquiatra do Hospital do Juquery Osório César, reconhecido por sua relação com a psicanálise, teria sido discípulo de Pacheco e Silva, o que mostraria, portanto, a abertura de Pacheco para a área. Ora, Osório César nunca foi discípulo de Pacheco e Silva, apenas trabalhou sob sua direção (Carvalho; Reily, 2010).

Outra vertente, ilustrada pelos trabalhos de Oliveira (2006), Tarelow (2011), Assumpção Júnior (2003), Abrão (2001), Nosek et al. (1994), Sagawa (1989) e Marcondes (1955), mostra que Pacheco e Silva teria sido contrário à psicanálise. Ainda assim, são trabalhos que também carecem de documentação histórica mais robusta - com exceção de Tarelow (2011, p. 104) que cita um documento escrito por Pacheco e Silva sobre o "valor dar modernas escolas psicológicas", que apresentariam suas "doutrinas hipotéticas"; do mesmo modo, Oliveira (2006) apresentaria os debates sobre o congresso de 1954 correndo nessa direção. Porém, um parecer de Marcondes citando o próprio Pacheco e Silva ainda possibilitaria outra leitura interpretativa:

Dou como exemplo, o Prof. A. C. Pacheco e Silva, o qual, em seu livro didático ensina a seus alunos que, entre os métodos da psicanálise mais em voga figuram a condenação, a transferência afetiva, a sublimação, a prática sexual normal. (Pacheco e Silva, 1940 apud Marcondes, 1955, p. 13)

Diante dessas referências, em larga medida contraditórias, julgamos que tais versões, ainda que importantes, não são suficientes para o esclarecimento desse impasse histórico. Os autores citados analisaram poucos documentos do próprio Pacheco, sustentando suas opiniões principalmente a partir de inferências e interpretações sem clara conexão com as fontes históricas, imprescindíveis para essa disciplina.

\section{Exagero das interpretações psicanalíticas ou incômodo com a presença de psicanalistas?}

Sabe-se que Pacheco e Silva inicia seus estudos na Faculdade de Farmácia e Bioquímica do Rio de Janeiro, transferindo-se para a medicina após o primeiro ano da graduação. No mesmo ano em que Freud publica o capital texto sobre a análise leiga, Pacheco e Silva (1926) lança seu primeiro livro, $A$ assistência a alienados nos Estados Unidos e na Europa, como um relatório de viagem apresentado ao Dr. José Manoel Lobo. À época, contava Pacheco 28 anos de idade, sendo diretor do Hospital do Juquery desde 1923. A lista de centros visitados inclui hospitais e clínicas nos Estados Unidos e na Europa, como os prestigiados centros franceses de Sainte Anne e Pitié-Salpetrière e a clínica Burghölzli, na Suíça (locais de forte presença psicanalítica).

O livro impressiona pela riqueza de detalhes na descrição dos serviços visitados, desde sua organização burocrática até a vigilância, passando pelo equipamento técnico e profissional. Pacheco e Silva (1926) dá especial destaque aos laboratórios, à presença da higiene mental e aos regulamentos. Essa ausência contradiz os trabalhos que mostram a presença da psicanálise nas mesmas instituições visitadas por Pacheco, como vemos nestes exemplos: Burghölzli - Eugen Bleuler usava a psicanálise desde 1907 (Dalzell, 2007); Sainte Anne - Henri Claude tornou-se seu chefe em 1922, sendo ferrenho defensor do freudismo (Roudinesco; Plon, 1998); e Estados Unidos: há presença da psicanálise no país desde 1909, com a visita de Freud à Clark University (Worcester, Massachusetts) (Otto, 2013).

A falta de qualquer menção à psicanálise é importante, pois ele dirigia o principal hospital psiquiátrico de São Paulo e viajou com o intuito de buscar o que havia de essencial na psiquiatria mundial. Consciente ou inconscientemente, Pacheco 
retira de seu relatório a presença da psicanálise nas principais instituições psiquiátricas do mundo, o que era publicamente reconhecido na época (Roudinesco, 2016).

Durante os anos 1930-1940, a psicanálise expandiu-se pelo mundo em ritmos diferentes e de maneiras diversas. Sua chegada ao Brasil se dá pela mão de médicos e por sua presença nos movimentos culturais, com particularidades locais. No caso paulista, ela encontraria um contexto que a favoreceria, como o movimento modernista, a criação da Universidade de São Paulo e o próprio crescimento da cidade, na qual os problemas psicológicos passariam a ocupar mais espaço (Oliveira, 2006).

Cabe destacar que, nesse contexto, a psicanálise encontraria uma psiquiatria encabeçada por Pacheco e Silva, que buscava imprimir políticas higienistas e eugenistas. A eugenia foi incorporada como termo médico-científico e, assim, se introduziu nas diversas especialidades, demarcando estratégias na busca de um homem ideal, reconhecido em sua individualidade para ser modificado, pois dizia-se que nem todos tinham as mesmas chances de ascender de seu estado considerado mórbido e degenerado. Dos estudos obstétricos às ações dos cirurgiões, das práticas sanitárias às experiências implementadas pelos psiquiatras, todos incorporaram a eugenia em seus cotidianos (Marinho; Mota, 2013).

Esse embate entre "as eugenias" pode ser acompanhado por diversas interpretações, das políticas às filosóficas, das religiosas às científicas. Todas, porém, em torno das questões que concentravam dois debates: aqueles que entendiam que as ações ambientais seriam capazes de equacionar a formatação do "homem bom" e aqueles que tinham na hereditariedade e na genética as únicas formas de se modelar um homem dentro de um projeto de melhoria racial (Mota, 2003; Stepan, 2005). Como deputado parlamentar em 1934, Pacheco e Silva centrava suas ideias na tentativa de purificar a raça, adotando um discurso radical e buscando implementar ações concretas (Pacheco e Silva, 1934) para que esse modo de pensar o mundo se impusesse.
A luta, o combate, a segregação, o afastamento dos indesejáveis, incuráveis ou menos favorecidos eram argumentos reiteradamente utilizados por ele: “a urgência de se cuidar do aperfeiçoamento da raça” (Pacheco e Silva, 1934, p. 11).

Se o higienismo de Pacheco caminhou nessa direção, o higienismo de Durval Marcondes tomou outro rumo, estruturando o Serviço de Higiene Mental Escolar do município, que seria uma porta de entrada para a psicanálise. Segundo Oliveira (2006), Pacheco e Durval travam uma relação de disputa como herdeiros de Franco da Rocha. De fato, suas divergências têm início anos antes, em 1930, e tangem o papel da psicanálise. Franco da Rocha chega a escrever cartas a Marcondes aconselhando-o a não debater tais questões publicamente com Pacheco, o que "só alimentaria o público sedento de embates entre médicos":4

\section{Figura I - Carta de Franco da Rocha para Durval Marcondes em 1930, abordando as discussões entre Pacheco e Durval}

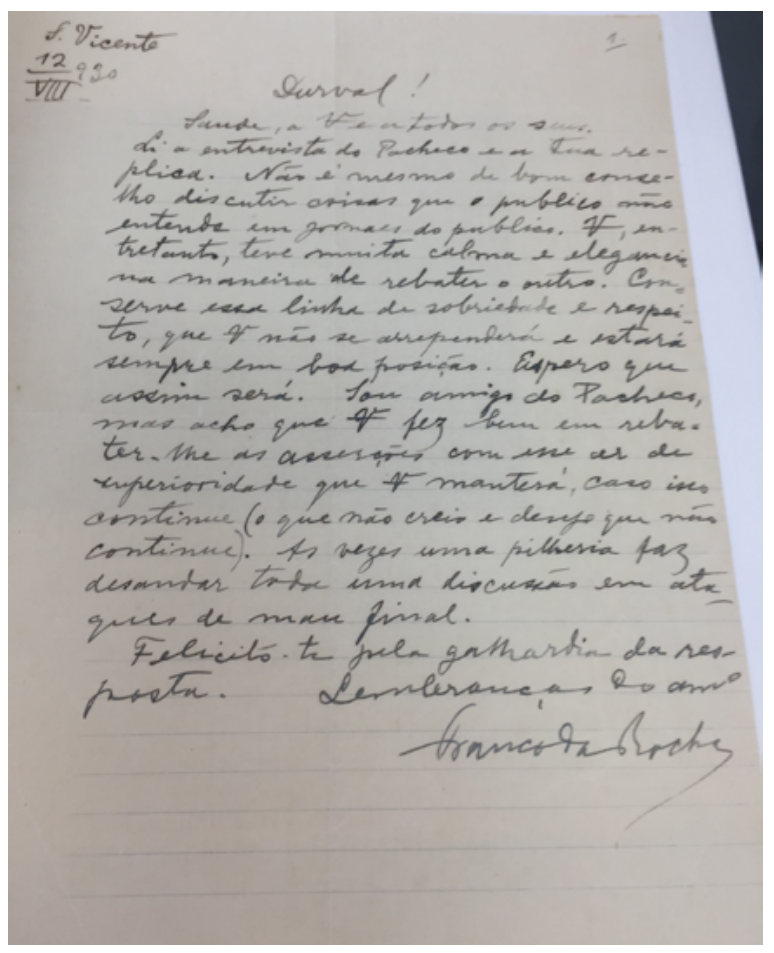

Fonte: Franco da Rocha. ${ }^{5}$ 
As disputas com Durval ilustram as reservas de Pacheco diante não só da psicologia, mas principalmente de seus praticantes. Seu discurso exalta o papel da psiquiatria e o avanço das pesquisas fisiológicas que se reflete nas doenças do espírito: a moderna semiologia médica não poderia prescindir dos exames de laboratório, da herança biológica e do estudo do cérebro.

Ao mesmo tempo, a psicologia era uma realidade incontornável e a psicoterapia uma "influência da confiança, da fé, sobre o resultado do tratamento”, na qual o médico, para "arrancar os doentes do abatimento moral em que tantas vezes se encontram", infunde-lhes "novas esperanças para que suas prescrições sejam obedecidas" (Pacheco e Silva, 1950, p. 49). No mesmo livro de 1950, encontramos a conferência "A segunda revolução psiquiátrica”, na qual Pacheco exalta o avanço da psiquiatria - num primeiro tempo, com Pinel e a verdadeira assistência aos doentes mentais (Pacheco e Silva, 1950); depois, no terreno da terapêutica: "Realmente, foram os progressos da Bioquímica, da Endocrinologia, da Psicologia, da Anatomia Patológica e da Terapêutica que contribuíram para o extraordinário impulso recebido pela Psiquiatria" (Pacheco e Silva, 1950, p. 332). No mesmo texto, diz: "Não se poderia deixar de assinalar o mérito invulgar de Sigmund Freud, cuja obra psicanalítica, despida dos seus exageros, permanecerá imperecível, como uma das contribuições mais preciosas para a sondagem do espírito humano" (Pacheco e Silva, 1950, p. 334).

A brevíssima menção a Freud assinala a diferença entre a genialidade do homem e o valor de sua obra, a psicanálise, sempre referida como exagerada ou excessiva. Esse é o modelo da crítica de Pacheco: uma afirmação que contém uma negação, a qualificação de Freud e a desqualificação direta ou indireta do campo psicanalítico, na imensa maioria das referências. A exceção se observa na página 344, quando ele menciona a pertinência de uma conferência de Anna Freud.

Em outro artigo desse livro, baseado numa palestra na União Cultural Brasil-Estados Unidos, proferida em 1941, sobre o retorno aos Estados Unidos 15 anos depois da primeira expedição, de 1926, ele se maravilha com o "incessante dinamismo dos psiquiatras americanos”, constatando o incrível aumento do aparelhamento técnico e humano da psiquiatria estadunidense. Alinhando-se ao que concebe como avanço inexorável da moderna psiquiatria, felicita-se ao verificar que tem feito no Brasil o que observou nos Estados Unidos - houve inclusão de laboratórios, incursão no ensino médico, institucionalização da psiquiatria e críticas à psicanálise:

\begin{abstract}
A Psicanálise
A psicanálise teve grande surto dos Estados Unidos logo após a divulgação das teorias de Freud, como pude apreciar [mas não descrever] na minha primeira viagem aos Estados Unidos há 15 anos passados. Após o entusiasmo inicial, a questão passou a ser encarada sob certas reservas e já não se nota, entre os americanos, a mesma confiança na terapêutica pela psicanálise. 0 próprio povo revela certa prevenção contra esse método curativo, que deu lugar a verdadeiras explorações por parte de certos psicanalistas, nem sempre devidamente esclarecidos. Entretanto, é preciso reconhecer a existência de grupos isolados, que seguem religiosamente os princípios de Freud, admitindo a sua doutrina sem discussão. São os discípulos ortodoxos de Freud. (Pacheco e Silva, 1950, p. 385)
\end{abstract}

Fica bastante evidente a posição de Pacheco e sua forma de enxergar a relação da psicanálise com a cultura, mesmo que brevemente, e sobretudo com a psiquiatria. Não obstante as inúmeras críticas à psicanálise, é historicamente incorreto afirmar que nos 1940 a psicanálise estadunidense caducava (Mezan, 2014). Zaretsky (2006) afirma que a grande expansão da psiquiatria estadunidense no pós-Segunda Guerra (em 1948, existiam 4.800 psiquiatras) liga-se diretamente à expansão da psicanálise (aproximadamente 400 psicanalistas). Esses psicanalistas encabeçam o movimento reformista ou psicodinamista, que traz à tona a realidade do modelo manicomial e a precária situação de muitas instituições psiquiátricas na época. É importante ressaltar que foi justamente nos Estados Unidos que a comunidade médica rejeitou a prática de psicanálise por não médicos; assim, praticamente todos os psicanalistas da época, 
ligados à IPA, eram médicos, e sua imensa maioria, psiquiatras:

Como os psiquiatras eram chefes de departamento nos hospitais e supervisionavam os assistentes sociais e psicólogos clínicos, o alcance da análise não era pequeno [...]. Portanto, em todas as áreas, a análise teve importância capital na reorganização social do pós-guerra (Zaretsky, 2006, p. 265)

O autor afirma que a influência psicanalítica na sociedade estadunidense declina ao longo da década de 1960, pelo menos 20 anos após o texto de Pacheco.

Ainda em outro texto, ele comenta o I Congresso Internacional de Psiquiatria, realizado em Paris, em 1950, e faz duas menções à psicanálise: na primeira, dá sua visão sobre a explicação freudiana para os delírios sistematizados e, numa impressionante redução conceitual, diz que, "Segundo Freud e seus discípulos, os delírios sistematizados nada mais representam senão a expressão de um homossexualismo inconsciente" (Pacheco e Silva, 1950, p. 463); em seguida, escreve:

A evolução e as tendências atuais da psicanálise tiveram como relatores Franz Alexander, A. Freud, M. Levine e R. de Saussure. Alexander, ao analisar a evolução da psicanálise, dividiu em três períodos principais as suas diversas etapas: a descoberta da dinâmica das forças do inconsciente; o desenvolvimento dos métodos apropriados ao estudo dos processos inconscientes e o estudo das funções do eu. Ana Freud ocupou-se, sobretudo, da psicologia psicanalítica da criança. Levine analisou as tendências da psicanálise nos Estados Unidos, cuja associação psicanalítica tem hoje autonomia própria com relação à organização psicanalítica internacional, mostrando a importância das relações da psicanálise com a psiquiatria e a medicina psicossomática. (Pacheco e Silva, 1950, p. 469)

Pacheco procura mostrar que se discutiram no congresso os problemas da repartição da psiquiatria da época em duas escolas "aparentemente díspares em que se dividiam os psiquiatras de várias gerações: a somática e a psicológica" (Pacheco e Silva, 1950, p. 462). Na mesma época, empenha-se para criar na
FM-USP a cadeira de Psicossomática, que reuniria de forma "clara e insofismável corpo e espírito" (Pacheco e Silva, 1950, p. 463). A parca exploração de Pacheco sobre as concepções psicanalíticas do conceito de delírio tem efeito claramente negativo na difusão da psicanálise e está alinhada com a maneira como ele divulga a maioria das informações sobre aquela área. A neutralidade da segunda informação permite constatar que o Congresso de Paris incluiu a psicanálise no seio de suas discussões, o que coincide com a historiografia do campo (Sabshin, 1990, p. 1270). Vale lembrar que em 1952 seria lançado o Manual Diagnóstico e Estatístico de Transtornos Mentais, segunda revisão (DSM II), manual de diagnóstico psiquiátrico estadunidense com visível influência psicanalítica (Dunker; Kyrillos Neto, 2011, p. 614).

Em outra coletânea, o livro A psiquiatria e a vida moderna, lemos isto no capítulo "O renascimento da medicina pelo espírito":

Razão assiste, pois, a Pierre Janet, quando ao criticar os métodos terapêuticos derivados do magnetismo, faz severos reparos à psicanálise, mas conclui: "É interessante notar que se trata de um método psicoterápico cujas raízes mergulham no magnetismo animal francês. A psicanálise é hoje a última encarnação dessas práticas, ao mesmo tempo mágicas e psicológicas, que caracterizam o magnetismo: conserva ela os mesmos caracteres, a imaginação e a ausência de crítica, a ambição avassaladora, o cunho epidêmico, a luta contra a ciência oficial. É provável que ela venha a conhecer também apreciações injustas, mas como o magnetismo e o hipnotismo, terá desempenhado grande papel e dado útil impulsão aos estudos psicológicos”. É digna de encômios a elevação de espírito com que Janet comenta essas questões, reconhecendo os méritos de seu maior antagonista (Pacheco e Silva, 1948, p. 57)

Mesmo que nesse texto Pacheco tenha se apoiado nas ideias de Pierre Janet e incluído Freud, dizendo-o, no parágrafo imediatamente anterior ao citado, um dos responsáveis por “atrair a atenção de todos para o estudo do consciente e das suas relações com o subconsciente" (Pacheco e Silva, 1948, p. 56-57), e 
argumentando que o próprio Freud se tenha referido à psicanálise como feiticeira, o teor do texto é de contraposição. No conjunto, o artigo exalta a presença da psicologia na medicina por meio da psicossomática e da atitude de médicos que não poderiam mais relegar os aspectos psíquicos dos doentes. Contudo, na lógica da superação histórica, a psicanálise é dada como etapa de um longínquo passado, quando se misturavam ciências e "pseudociências". Evidentemente, Pacheco não confere à psicanálise o estatuto de ciência e despreza qualquer consideração de Freud ou de outros psicanalistas sobre a questão.

É também curioso notar que o hipnotismo aparece destituído da relevância que lhe imputa Pacheco, e não a psicanálise (Pacheco e Silva, 1948). Vigoroso defensor da hipnose, o psiquiatra cultua o retorno do método com o aporte científico da década de 1950, ainda que o discurso não acompanhe a prática efetiva e que seus tratamentos por hipnose, ainda nos anos 1940-1960, se baseiem em crenças pessoais. A hipnose é importante na concepção de Pacheco, pois, justamente com seu militarismo e sua religiosidade, ela faz a ponte para o que ele concebia como psicoterapia: métodos persuasivos de mudança de comportamento dos doentes. "As forças espirituais são grandes alavancas que concorrem para a aceleração dos processos normais de cura de todas as doenças. A fé move montanhas e é um fator indispensável à felicidade humana" (Pacheco e Silva, 1948, p. 181).

Diante disso, podemos compreender que parte da psicanálise se confrontava com as principais ideias de Pacheco, pois não buscava segregar, selecionar, restringir ou normatizar o homem (Marcondes, 1955; Mezan, 2014). Ainda assim, o saber psicanalítico também foi usado para embasar algumas práticas higienistas, como no caso do Rio de Janeiro (Costa, 2007), e influenciou a psiquiatria na direção da compreensão da vida psíquica, da infância, da sexualidade, da emancipação das pessoas e na abertura de horizontes dentro da própria psiquiatria, como no movimento que levou à constituição da noção de saúde mental, iniciado nos Estados Unidos nos anos 1940 (Zaretsky, 2006).

\section{Psicanálise rechaçada por Pacheco}

Em 1953, Pacheco publica "Apreciações da psicanálise”, um artigo em que explicita claramente suas opiniões.

\section{Figuras 2 e 3 - Artigo de Pacheco e Silva: "Apreciações da psicanálise"}

\section{Apreciações da psicanálise}
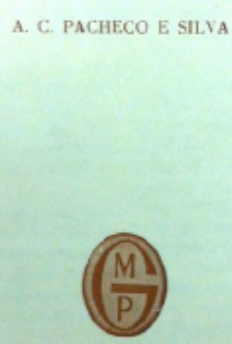

CAZETA MEDICA DORTUCUESA

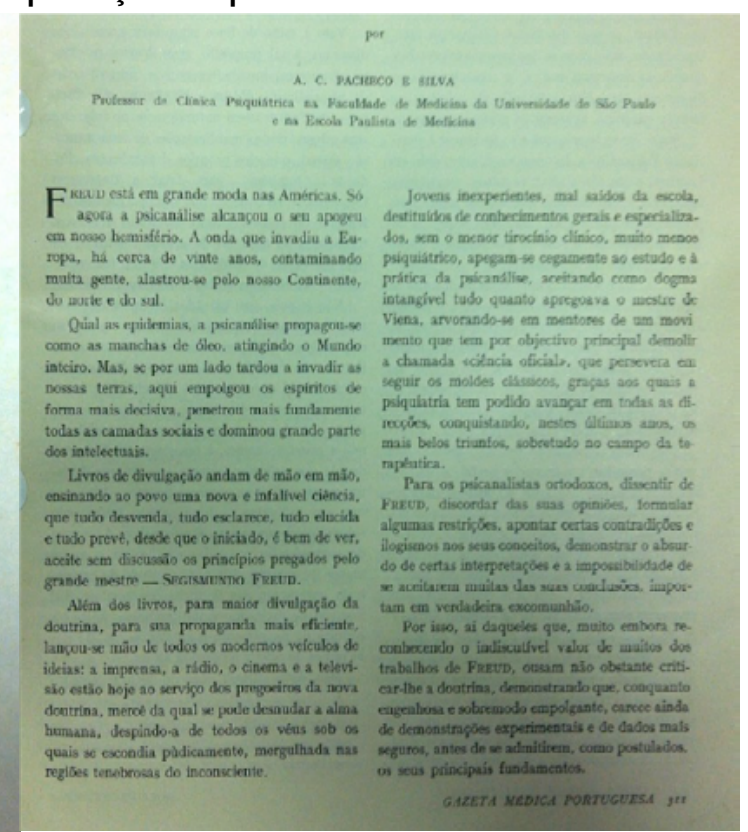

Fonte: Pacheco e Silva (1953). 
A publicação na Gazeta Médica Portuguesa, em 1953, antecede o acalorado debate que se travaria entre 1954 e 1955 sobre o exercício da psicanálise por não médicos no Brasil (Congresso LatinoAmericano de Saúde Mental, 1954). O periódico faria circular ideias de um texto duro, cujo autor, gozando do prestígio político e científico de sua posição, se faz porta-voz de uma indignação contra a "peste" psicanalítica. Mais uma vez, ele constata a ampla disseminação da psicanálise pelo mundo, o que reforça a hipótese de que sua omissão da psicanálise nos textos anteriores não foi casual. A figura de Freud, que já fora citada de forma elogiosa, surge mais ambivalente, como o líder que não aceita contestação ou crítica. É explícito o incômodo de Pacheco com os seguidores "submissos" de Freud que formaram a Associação Psicanalítica Internacional.

Assim, todo aquele que não pertencer à Associação Psicanalítica Internacional, com sede em Londres e que não aceitar, in totum, o catecismo freudiano, e, ao demais, que não tenha feito previamente psicanalisar, não tem sequer o direito de empregar a palavra psicanálise e muito menos intitular-se psicanalista. Só os membros daquela organização são os legítimos detentores da ciência secreta e podem exercê-la como verdadeiros intérpretes de Freud. A psicanálise tornou-se, destarte, numa verdadeira seita, monopólio de um grupo, no qual são admitidos apenas uns tanto predestinados dotados de atributos especiais, únicos capazes de entendê-la e, sobretudo, de praticá-la.

Todos aqueles que têm a audácia de discordar de Freud não tardam em receber a merecida lição. Uns são votados ao mais completo desprezo e taxados de retrógrados, atrasados, fossilizados, incapazes de uma visão mais ampal, que lhes permita conceber as bases da psicollogia dinâmica, de compreender a estrutura da personalidade. (Pacheco e Silva, 1953, p. 326)

A argumentação é sustentada no fato de haver muitos críticos ao pensamento de Freud - que afirmam estar a psicanálise exageradamente calcada na questão sexual - e à estratégia de psicanalistas de não responderem críticas feitas ao seu trabalho.
O psiquiatra paulista encerra suas observações dizendo que é fácil entender o sucesso da psicanálise como mais uma entre as panaceias das crendices em magia e hipóteses inconsistentes.

Pacheco afirma que sua inabalável busca pela verdade e sua falta de preconceitos levaram-no a escrever essa crítica para advertir as futuras gerações dos perigos da psicanálise, uma matéria fácil e sedutora, que cativa jovens ansiosos e charlatães.

Animado por profunda convicção, movido pelo único objetivo de buscar a verdade, despido de todo e qualquer preconceito, abalancei-me a escrever esta crítica, sem outro fim que não o de alertar as gerações novas, para que se não deixem arrastar por teorias altamente sedutoras, que exercem indiscutível impressão sobre os espíritos jovens, ansiosos por encontrar soluções para problemas complexos ante os quais se debatem. (Pacheco e Silva, 1953, p. 323)

Para o psiquiatra, mesmo que se auferisse algum valor do método psicanalítico, ele ainda seria inferior às técnicas de persuasão e sugestão. Epidemia, alarme, risco, enganação, sedução, desprezo à psiquiatria organicista e ortodoxia sustentam sua argumentação contra a psicanálise:

Se no terreno da indagação psicológica dos métodos psicanalíticos constituem um instrumento de indiscutível valor, no terreno terapêutico as suas técnicas são indiscutivelmente inferiores às demais técnicas psicoterápicas, da persuasão e da sugestão, empregadas com notável êxito pelas grandes figuras do passado e do presente. (Pacheco e Silva, 1953, p. 325)

Essa visão é coerente com a que tem da psicoterapia, mostrada em outros textos, como "Psicoterapia básica" (Pacheco e Silva, 1959), no qual, novamente apoiando-se em outros autores, diz que a melhor definição para a psicoterapia seria de Joseph Grasset: "Psicoterapia é o tratamento das doenças pelos meios psíquicos, quer seja pela persuasão, sugestão, emoção, distração, fé, predicação ou, em uma palavra, pelo pensamento e tudo que com ele se relacione" (Grasset, 1911 apud Pacheco e Silva, 1959, p. 289). Pacheco percebe a especificidade do 
campo psicanalítico, separando-o das demais formas de psicoterapia - e, no mesmo texto, afirma que "as técnicas psicanalíticas visam em sua essência, tornar conscientes os conflitos inconscientes e libertar o doente de carga emocional que o traz sob permanente tensão" (Pacheco e Silva, 1959, p. 293).

\section{"Psicanálise a mistificação do século"}

Em 1965, o casal Pinckney escreve Psicanálise: a mistificação do século, um livro dedicado a criticar todo e qualquer aspecto da psicanálise. Parte da psiquiatria, que se havia beneficiado do repertório psicanalítico entre os anos 1930-196o, começava a se afastar dele. Tratam-se de anos que envolvem debates, críticas e redirecionamentos. A publicação do DSM III, em 1980, marcou a entrada na era da farmacologia, bem como o afastamento da psicanálise, ao excluir grande parte da terminologia psicanalítica de seu conteúdo. A chamada "geração Prozac" se sustentava nas mudanças que criaram fármacos mais fáceis de administrar, mais toleráveis e eficientes. Estes, por sua vez, implicaram uma mudança radical na orientação de parte da psiquiatria, que se afastou das correntes psicológicas para entrar na era dos manuais diagnósticos.

Ainda assim, a psicanálise penetrara inapelavelmente na cultura, e era imperioso combatê-la, como atesta a publicação do casal de médicos estadunidenses. Traduzido para poucos idiomas, o livro é editado em português no Brasil em 1970, com prefácio de Pacheco e Silva. Aposentado, com a vida profissional em declínio e sérios problemas pessoais, o psiquiatra reiterou suas opiniões contra a psicanálise:

A grande maioria dos seus adeptos, afeiçoados e propagandistas, entrega-se ilegalmente ao exercício da medicina, como bem assinala Pinckney, transformando um apostolado em comércio ilícito e condenável. É o que o autor deste livro demostra de forma cabal, buscando alertar os incautos e clamar às autoridades para que ponham um paradeiro a uma das maiores e mais perniciosas mistificações deste século. (Pacheco e Silva, 1970, p. 12)

Esse prefácio não ressoa com a ampla difusão da psicanálise em território brasileiro na época, chamada por Coimbra (1995) de boom da psicanálise. Pacheco se alinha ao que ocorria principalmente nos Estados Unidos, com mudanças nos departamentos de Psiquiatria das principais escolas de medicina e a intensificação da pressão de psicólogos para exercerem a psicanálise naquele país. No Brasil, mesmo com os desmandos da ditadura civil-militar cabalmente escancarados com o Ato Institucional $n^{0}$ 5 (AI-5), de 1968, verifica-se um aumento crescente na demanda por atendimentos em psicoterapia e psicanálise (Oliveira, 2006).

A influência de Pacheco, portanto, não era absoluta. A EPM, chefiada por ele durante 30 anos, viu crescer um importante centro psicanalítico sob a coordenação da equipe liderada por Darcy de Mendonça Uchôa, que em 1964 derrotaria o candidato de Pacheco, João Carvalhal Ribas, no concurso para professor catedrático de psiquiatria da Escola, encerrando um largo ciclo organicista (Alarcão, 2018). Psicanalista e psiquiatra influente, Uchôa abriu espaço para o diálogo entre psicanálise e psiquiatria na instituição. Na FM-USP, Pacheco não impediu a criação de um Serviço de Psicoterapia entre 1962-1965. O psiquiatra garantiu a vigilância institucional da psicanálise, que galgava maiores espaços (Alarcão; Mota; Lotufo Neto, 2016).

\section{Considerações finais}

Nas tensões que formaram e influenciaram o campo psi, os discursos políticos e ideológicos acompanharam os debates científicos numa intricada rede de interesses e posições de diversos matizes. Por meio da documentação apresentada e dos estudos que vêm sendo realizados, pudemos nos aproximar de uma compreensão mais qualificada da ação de Pacheco e Silva sobre a psicanálise, em sua maioria mais pautada mais por suas convicções pessoais e pela força de suas posições políticas do que por argumentação científica. 0 seu pensamento abarcou desde a defesa da eugenia em suas formas mais intervencionistas nos anos 1923-1950 (Bertucci, 2013) até o remodelamento da psiquiatria de sua época, numa direção cada vez mais neuroquímica, uma das principais bases para a psiquiatria paulistana - o que de alguma maneira criou uma interpretação própria. 
Em vários textos, comprova-se seu interesse por psicanálise, em particular pela sexualidade, pela submissão dos psicanalistas a Freud, pela organização institucional dos psicanalistas e pela luta para que a psicanálise fosse exercida exclusivamente por médicos. Ao mesmo tempo, defende seu conceito de psicoterapia e a inegável correlação entre corpo e mente, por meio de sua atuação como hipnotizador e da implantação da cadeira de Psicossomática na FM-USP. Sua visão de psicoterapia sustenta-se na lógica da persuasão e de sugestões que buscam incutir nos pacientes as escolhas e visões dos médicos (que seriam psicoterapeutas por natureza e naturalmente habilitados a desempenhar essa função) e no dote natural e inquestionável dos médicos para essa prática, indicando uma continuidade com a maneira pela qual outros médicos e outras escolas médicas concebiam a psicoterapia (Alarcão, 2018; Garcia, 1942; Mezan, 2014).

A história do heterogêneo campo psi deve ser esmiuçada para que as críticas contemporâneas não omitam fatos e tampouco criem versões historicamente incorretas, como as que negam a oposição de Pacheco e Silva à psicanálise. Em vários textos do psiquiatra, verificamos que, muito mais do que resguardar o campo da ação de charlatães, havia uma nítida interpretação de que a psicanálise seduzia jovens médicos, sustentava-se em teorias inconsistentes e não se sujeitava à hierarquia da psiquiatria organicista, algo considerado inadmissível.

Não é possível, portanto, assumir que Pacheco e Silva apenas criticava a psicanálise cientificamente; ele o fazia sobretudo política e ideologicamente, como demonstrado pelos vários documentos históricos apresentados anteriormente. Cumpre entender historicamente como essas críticas e oposições influenciaram na organização subsequente do campo psi, constatando que a psiquiatria buscou se afastar das correntes de pensamento psicológico não organicistas a partir dos anos 1980 (Dunker; Kyrillos Neto, 2011).

\section{Referências}

ABRÃO, J. L. F. A história da psicanálise de crianças no Brasil. São Paulo: Escuta, 2001.

ALARCÃO, G. G. Na contracorrente? Resistências, adaptações e apropriações: a formação do Serviço de Psicoterapia do Instituto de Psiquiatria do Hospital das Clínicas da Faculdade de Medicina da Universidade de São Paulo - 1962-1965. 2018. Tese (Doutorado em Ciências) - Universidade de São Paulo, São Paulo, 2018.

ALARCÃO, G. G.; MOTA, A.; LOTUFO NETO, F. Formation of Psychoterapy Service of FMUSP Psychiatry Institute: a brief historiographical approach. Revista de Medicina, São Paulo, v. 95, n. 2, p. 93-100, 2016. Número especial.

AMARO, J. W. F. A história do Instituto de Psiquiatria do Hospital das Clínicas e do Departamento de Psiquiatria da Faculdade de Medicina da Universidade de São Paulo. Archives of Clinical Psychiatry, São Paulo, v. 3o, n. 2, p. 44-71, 2003.

ASSUMPÇÃO JÚNIOR, F. B. A ideologia na obra de Antônio Carlos Pacheco e Silva. Revista Latinoamericana de Psicopatologia Fundamental, São Paulo, v. 6, n. 4, p. 39-53, 2003.

BERTUCCI, L. Sanear a raça pela educação: teses da Faculdade de Medicina e Cirurgia de São Paulo, início dos anos 1920. In: MOTA, A.; MARINHO, M. G. S. M. D. (Org.). Eugenia e história: ciência, educação e regionalidades. São Paulo: Casa de Soluções, 2013. p. 219-238.

BOURDIEU, P. Usos sociais da ciência: por uma sociologia do campo científico. São Paulo: Editora Unesp, 2003.

CARVALHO, R. C. M.; REILY, L. Arte e psiquiatria: um diálogo com artistas plásticos no Hospital Psiquiátrico de Juqueri. ArtCultura, Uberlândia, v. 12, n. 21, p. 165-80, 2010.

COIMBRA, C. M. B. Guardiães da ordem: uma viagem pelas práticas psi no Brasil do "milagre". Rio de Janeiro: Oficina do Autor, 1995.

CONGRESSO LATINO-AMERICANO DE SAÚDE MENTAL, 1., 1954, São Paulo. Atas... São Paulo: Associação Paulista de Medicina, 1954.

COSTA, J. F. História da psiquiatria no Brasil: um corte ideológico. 5. ed. Rio de Janeiro: Garamond, 2007.

DALZELL, T. T. G. Eugen Bleuler 150: Bleuler's reception of Freud. History of Psychiatry, Thousand Oaks, v. 18, n. 4, p. 471-482, 2007. 
DUNKER, C. I. L.; KYRILLOS NETO, F. A crítica psicanalítica do DSM-IV: breve história do casamento psicopatológico entre psicanálise e psiquiatria. Revista Latinoamericana de Psicopatologia Fundamental, São Paulo, v. 14, n. 4, p. 611-626, 2011. Disponível em: <http://bit. ly/2XayjXn>. Acesso em: 2 fev. 2018.

FOUCAULT, M. Microfísica do poder. 22. ed. Rio de Janeiro: Graal, 2006.

FRANCO DA ROCHA, F. A doutrina de Freud. 2. ed. São Paulo: Companhia Editora Nacional, 1930.

FREIDSON, E. Profissão médica: um estudo de sociologia do conhecimento aplicado. São Paulo: Editora Unesp, 2009.

FREUD, S. A questão da análise leiga. In: FREUD, S. Edição standard brasileira das obras psicológicas completas de Sigmund Freud. Rio de Janeiro: Imago, 2006. v. 20. p. 203-293.

GARCIA, J. A. Compêndio de psiquiatria. Rio de Janeiro: A Casa do Livro, 1942.

MAIO, M. C. Educação sanitária, estudos de atitudes raciais e psicanálise na trajetória de Virgínia Leone Bicudo. Cadernos Pagu, Campinas, n. 35, p. 309-355, 2010.

MARCONDES, D. B. Parecer sobre o exercício da psicoterapia por psicólogos clínicose psicanalistas não formados em medicina. São Paulo: Edance, 1955.

MARINHO, M. G. S. M. D.; MOTA A. Tramas e teias da retórica eugênica em São Paulo: personagens, contextos e instituições médicas (1916-1954). In: MOTA, A.; MARINHO, M. G. S. M. D. (Org.). Eugenia e história: ciência, educação e regionalidades. São Paulo: Casa de Soluções, 2013. p. 201-218.

MEZAN, R. O tronco e os ramos. São Paulo: Companhia das Letras, 2014.

MORETZSOHN, M. A. Fundação da Sociedade Brasileira de Psicanálise de São Paulo. Jornal de Psicanálise, São Paulo, v. 48, n. 89, p. 241$244,2015$.

MOTA, A. Quem é bom já nasce feito: sanitarismo e eugenia no Brasil. Rio de Janeiro: DP\&A, 2003.
NEVES, A. C. O emergir do corpo neurológico no corpo paulista: neurologia, psiquiatria e psicologia em São Paulo a partir dos periódicos médicos paulistas (1889-1936). 2008. Tese (Doutorado em História Social) - Universidade de São Paulo, São Paulo, 2008.

NOSEK, L. et al. Álbum de família: imagens, fontes e idéias da psicanálise em São Paulo. São Paulo: Casa do Psicólogo, 1994.

OLIVEIRA, C. L. M. V. História da psicanálise: São Paulo (1920-1969). São Paulo: Escuta, 2006.

OTTO, T. St. Elizabeths Hospital: a history. Washington, DC: General Services Administration, 2013. Disponível em: <http://bit. ly/2UMyISg>. Acesso em: 2 fev. 2018.

PACHECO E SILVA, A. C. A assistência a alienados nos Estados Unidos e Europa. São Paulo: [s. n.], 1926.

PACHECO E SILVA, A. C. Direito à saúde:

documentos de atividade parlamentar. São Paulo: [s. n.], 1934.

PACHECO E SILVA, A. C. A psiquiatria e a vida moderna. São Paulo: Edigraf, 1948.

PACHECO E SILVA, A. C. Palavras de psiquiatra. São Paulo: Edigraf, 1950.

PACHECO E SILVA, A. C. Apreciações da psicanálise. Gazeta Médica Portuguesa, Carnaxide, v. 6, n. 2, p. 323-327, 1953.

PACHECO E SILVA, A. C. Psicoterapia básica.

Revista do Hospital das Clínicas, São Paulo, n. 14, p. 288-299, 1959.

PACHECO E SILVA, A. C. Prefácio. In: PINCKNEY, E. R.; PINCKNEY, C. Psicanálise: a mistificação do século. São Paulo: Edigraf, 1970. p. 9-12.

PEREIRA, M. E. C. A crise da psiquiatria centrada no diagnóstico e o futuro da clínica psiquiátrica: psicopatologia, antropologia médica e o sujeito da psicanálise. Physis, Rio de Janeiro, v. 24, n. 4, p. 1035-1052, 2014.

REIS, J. C. História e teoria: historicismo, modernidade, temporalidade e verdade. 3. ed. Rio 
de Janeiro: Editora FGV, 20o6. Disponível em: <http://bit.ly/2Gkkv6Z>. Acesso em: 2 fev. 2018.

ROUDINESCO, E. Sigmund Freud na sua época e em nosso tempo. Rio de Janeiro: Zahar, 2016.

ROUDINESCO, E.; PLON, M. Dicionário de psicanálise. Rio de Janeiro: Zahar, 1998.

SABSHIN, M. Turning points in twentiethcentury American psychiatry. The American Journal of Psychiatry, Arlington, v. 147, n. 10, p. 1267-1274, 1990.

SAGAWA, R. Y. Os inconscientes no divã da história. 1989. Dissertação (Mestrado em Filosofia e Ciências Humanas) - Universidade Estadual de Campinas, Campinas, 1989.

SEIXAS, A. A. A. Instituto de Psiquiatria FMUSP: o contexto histórico social em São Paulo entre as décadas de 1920 a 1950 para recepção da psiquiatria como um saber médico. 2012. Dissertação (Mestrado em Psiquiatria) Universidade de São Paulo, São Paulo, 2012.
SEVCENKO, N. A cidade metástasis e o urbanismo inflacionário: incursões na entropia paulista. Revista USP, São Paulo, n. 63, p. 16-35, 2004.

STEPAN, N. A hora da eugenia: raça, gênero e nação na América Latina. Rio de Janeiro: Fiocruz, 2005.

TARELOW, G. Q. Entre febres, comas e convulsões: as terapias biológicas no Hospital do Juquery administrado por Pacheco e Silva (1923-1937). 2011. Dissertação (Mestrado em História Social) - Universidade de São Paulo, São Paulo, 2011.

TORQUATO, L.; ROCHA, G. M. A peste no Brasil: a introdução das ideias freudianas no Brasil a partir da medicina e do modernismo. Ágora: Estudos em Teoria Psicanalítica, Rio de Janeiro, v. 19, n. 3, p. 425440, 2016.

ZARETSKY, E. Segredos da alma: uma história sociocultural da psicanálise. São Paulo:

Cultrix, 2006.

\section{Contribuição dos autores}

Alarcão concebeu e delineou o trabalho, redigiu o manuscrito e, com Mota, discutiu resultados, revisou e aprovou a versão final do artigo.

Recebido: 18/10/2018

Reapresentado: 06/02/2019

Aprovado: 28/02/2019 